\title{
FATIGUE BEHAVIOUR OF NODULAR CAST IRON AT VARIOUS LOADING CYCLE ASYMMETRY
}

Fatigue behaviour of nodular cast irons is described in specialized literature quite well but the majority of fatigue tests in high cycle region has been made at symmetrical bending or at symmetrical tension-compression loading. The role of loading cycle asymmetry is very important because the fatigue limit of nodular cast irons is substantially influenced by mean static stress. Unfortunately, the number of papers describing the influence of mean static stress is quite low. The aim of the presented paper consists in presenting the results of long-term research of nodular cast irons at high cycle region at different loading cycle asymmetry. Several heats with various heat treatments leading to various structures of matrix were used for fatigue tests performed mainly at symmetrical tension-compression loading and at repeating tensile loading. From $S$ - $N$ curves the fatigue limits for $10^{7}$ cycles were determined and then used for the calculation and construction of the Haigh and the Smith diagrams. Nodular cast irons seem to be more sensitive to mean static stress than structural steels. It was found that, in contrast to many papers, the dependence of upper stress on mean stress is not linear but parabolic with the exponent lower than 1 whose value is linear function of UTS.

\section{Introduction}

\subsection{Nodular cast iron}

Nodular cast iron and particularly its high-strength type called ADI (austempered cast iron) is very prospective structural material with worldwide increasing production. In European industrially developed countries its production increases by 5 to $10 \%$ every year, to the detriment of production of grey and tempered iron, cast steels, weldments, forgings etc. [1,2]. Besides excellent technological properties its advantage consists in favourable shape of graphite particles which, in comparison with other cast irons, does not decrease substantially the mechanical properties of metal matrix. Accordingly, various heat treatments are applied for nodular cast iron similarly as for usual structural steels and thus its mechanical properties can be changed in a wide range of strength and plasticity. Variability in the microstructure of cast iron matrix is even substantially wider than in the microstructure of steels because the graphite particles can work as stocks of carbon and, therefore, in one heat of cast iron wide range of ferritic-pearlitic mixtures can be obtained from purely ferritic to nearly purely pearlitic matrix.

Nodular cast iron can be used for many industrial components as e.g. gear wheels, valve levers of diesel engines, crankshafts, piston rods etc. Considerable part of its production is applied in military industry, above all for the details of military vehicles and some types of armour. Most of these products are loaded statically as well as dynamically and, therefore, the crucial role in degradation processes is played by mechanical fatigue. Relatively high number of data dealing with fatigue behaviour of nodular cast iron, which have been published, can be used only in a limited extent because they are neither complete nor uniform, sometimes they are even contradictory. It is a consequence of the fact that various test devices and various test bars have been used for fatigue tests performed according to different test procedures. Also different data processing of fatigue results has been applied, e.g. fit procedures of S-N curves including various numbers of cycles to fracture defining fatigue limit. Moreover, most high-cycle fatigue tests leading to determination of S-N curves and fatigue limits have been performed at symmetrical bending or at symmetrical push-pull loading. The influence of various asymmetry of loading cycle on fatigue behaviour of nodular cast iron has not been studied sufficiently widely in spite of the fact that fatigue limit of nodular cast iron depends very strongly on a static tensile stress component of the total loading stress.

\subsection{Influence of loading cycle asymmetry}

The value of fatigue limit is a function of loading cycle asymmetry and it increases or decreases according to the sign of mean stress. This fact is usually presented by the Smith or the Haigh diagram. While the Smith diagram expresses the dependence of extreme stresses of loading cycle (i.e. upper stress $\sigma_{h}$ and lower stress $\sigma_{n}$ ) on mean stress $\sigma_{m}$ of loading cycle, the simpler Haigh diagram determines the relation between the stress amplitude $\sigma_{a}$ and the mean stress $\sigma_{m}$. Both diagrams are mostly drawn for the number of cycles to fracture corresponding to the fatigue limit (usually $10^{7}$ cycles), but also the families of curves for various cycle numbers are presented.

For a simple estimation of the shape of both diagrams several relations were proposed describing the dependence of the maximum

\footnotetext{
* Stanislav Věchet ${ }^{1}$, Jan Kohout ${ }^{2}$, Klára Hanzlíková ${ }^{1}$, Vojtěch Hrubý ${ }^{3}$

${ }^{1}$ Institute of Materials Science and Engineering, Faculty of Mechanical Engineering, Brno University of Technology, 61669 Brno, Czech Republic, E-mail: vechet@umi.fme.vutbr.cz

${ }^{2}$ Department of Mathematics and Physics, Military Technology Faculty, University of Defence, 61200 Brno, Czech Republic

${ }^{3}$ Department of Mechanical Engineering, Military Technology Faculty, University of Defence, 61200 Brno, Czech Republic
} 
stress amplitude on the mean stress of loading cycle. A very often used type is

$$
\sigma_{a}=\sigma_{C}\left[1-\left(\frac{\sigma_{m}}{R_{m}}\right)^{\alpha}\right]
$$

with various values of exponent $\alpha$, which cover the range from 1 to 2 for most structural materials [6]. For $\alpha=1$ typical for highstrength steels and some types of cast irons with lamellar and nodular graphite the linear Goodman relation is obtained. The Gerber quadratic parabola for $\alpha=2$ is valid for low carbon, unalloyed or low alloyed steels.

The contribution presents the results of long-term research of high-cycle fatigue behaviour of several types of nodular cast iron with emphasis on various asymmetry of a loading cycle.

\section{Experiments}

Three heats of nodular cast iron marked 0,13 and 15 were used for fatigue tests [3]. Heats 0 and 15 were not alloyed, heat 13 was alloyed with $\mathrm{Cu}$. Chemical composition of all three heats is given in Table 1 . Heats 13 and 15 were heat treated in various ways and thus eight different matrices were obtained. Their marks consist of letters meaning heat treatment and of numbers meaning basic heat, e.g. BU13 means ADI with upper bainite matrix made of heat 13 .

Chemical composition of studied

Table 1

nodular cast irons (in wt \%)

\begin{tabular}{|c|c|c|c|c|c|c|c|}
\hline Heat & $\mathrm{C}$ & $\mathrm{Si}$ & $\mathrm{Mn}$ & $\mathrm{P}$ & $\mathrm{S}$ & $\mathrm{Mg}$ & $\mathrm{Cu}$ \\
\hline 0 & 3.26 & 2.06 & 0.11 & 0.020 & 0.008 & 0.057 & - \\
\hline 13 & 3.43 & 2.55 & 0.56 & 0.055 & 0.016 & 0.093 & 0.61 \\
\hline 15 & 3.46 & 2.10 & 0.25 & 0.047 & 0.002 & 0.058 & - \\
\hline
\end{tabular}

Feritization annealing was applied to heat 0 to obtain purely ferritic microstructure marked F0. Heats 13 and 15 were used as cast and marked as P13 (nearly purely pearlitic structure) and FP15 (ferritic-pearlitic structure). Isothermal transformation of heat 13 led to upper bainite BU13. Four matrices were obtained by heat treatment of heat 15: pearlite P15 by normalization annealing and upper bainite BU15, transient bainite BT15, and lower bainite BL15 by isothermal transformation.
Ferritization and normalization annealing was performed in electric muffle furnace. Heat treatment conditions are presented in Table 2. Austempering of ADI was performed in electric crucible furnaces. Austenitization was made at $900{ }^{\circ} \mathrm{C}$ during 1 hour in $\mathrm{GS} 530+\mathrm{C} 3$ salt bath, isothermal transformation was made at 400 (BU), 350 (BT) and $300{ }^{\circ} \mathrm{C}$ (BL) in AS140 salt bath. The dwells at transformation temperatures were chosen from a very wide temporal range 2 minutes to 25 hours to obtain the structure with maximum elongation to fracture [4]. Transformation conditions are given in Table 3 .

Structures and heat treatment conditions

Table 2 of ferritic-pearlitic nodular cast irons

\begin{tabular}{|c|c|c|c|c|}
\hline \multirow[t]{2}{*}{ Material } & \multicolumn{2}{|c|}{ Graphite particles } & \multirow{2}{*}{$\begin{array}{c}\text { Matrix } \\
\text { ferrite/pearlite [\%] }\end{array}$} & \multirow{2}{*}{$\begin{array}{l}\text { Heat treatment } \\
\text { conditions }\end{array}$} \\
\hline & shape & size $[\mu \mathrm{m}]$ & & \\
\hline F0 & VI & $30-60$ & $100 / 0$ & $\begin{array}{c}\text { ferritization } \\
\text { annealing } 870{ }^{\circ} \mathrm{C} \text {, } \\
11 \text { hours, furnace }\end{array}$ \\
\hline $\mathrm{P} 13$ & VI, V & $30-60$ & $4 / 96$ & as cast \\
\hline FP15 & VI, V & $30-120$ & $55 / 45$ & as cast \\
\hline P15 & VI, V & $30-120$ & $0 / 100$ & $\begin{array}{c}\text { normalization } \\
\text { annealing } 900^{\circ} \mathrm{C} \text {, } \\
1 \text { hour, air }\end{array}$ \\
\hline
\end{tabular}

Metallographic samples were prepared by standard procedure using heads of test bars after mechanical tests. The shape and size of graphite particles were determined using cuts before etching (VI means perfectly globular and $\mathrm{V}$ imperfectly globular grains). After etching in so called Nital $2 \%$ (solution of nitric acid in ethanol) the content of ferrite and pearlite in structure was evaluated. For observation of structure the Zeiss-Neophot 21 light microscope was used. Retained austenite in austempered matrix was determined using X-ray quantitative phase analysis in heads of cylindrical test bars, which were not deformed and their original structure was not changed by possible transformation of retained austenite due to tensile loading. Resulting structures are described in Table 2 (ferritic and pearlitic structures) and in Table 3 (austempered structures). Microstructure of ADI transformed at $400{ }^{\circ} \mathrm{C}$ is presented in various magnifications in Fig. 1 to 3 .

For the determination of basic mechanical properties (yield stress $R_{p 0.2}$, ultimate tensile strength $R_{m}$, elongation to fracture $A_{5}$ and reduction of area $Z$ ) at static tensile loading three or four

Structures and heat treatment conditions of austempered nodular cast irons

\begin{tabular}{|c|c|c|c|c|c|}
\hline \multirow[t]{2}{*}{ Material } & \multicolumn{2}{|c|}{ Graphite particles } & \multirow{2}{*}{$\begin{array}{c}\text { Matrix } \\
\text { austenite [\%] }\end{array}$} & \multirow{2}{*}{$\begin{array}{l}\text { Transformation } \\
\text { temperature }\left[{ }^{\circ} \mathrm{C}\right]\end{array}$} & \multirow{2}{*}{$\begin{array}{c}\text { Transformation } \\
\text { dwell [min] }\end{array}$} \\
\hline & shape & $\operatorname{size}[\mu \mathrm{m}]$ & & & \\
\hline BH13 & VI, V & $30-60$ & 41.9 & 400 & 50 \\
\hline BH15 & VI, V & $30-120$ & 34.4 & 400 & 40 \\
\hline BP15 & VI, V & $30-120$ & 19.9 & 350 & 100 \\
\hline BD15 & VI, V & $30-120$ & 9.5 & 300 & 60 \\
\hline
\end{tabular}




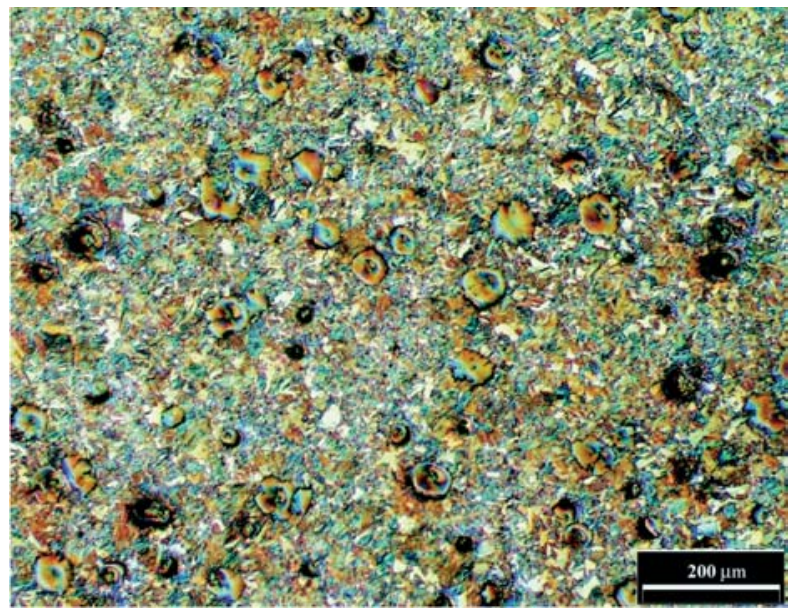

Fig. 1 Structure of ADI transformed during 40 minutes at $400{ }^{\circ} \mathrm{C}$. (Nital etching, the Nomarski method, actual magnification $100 x$ )

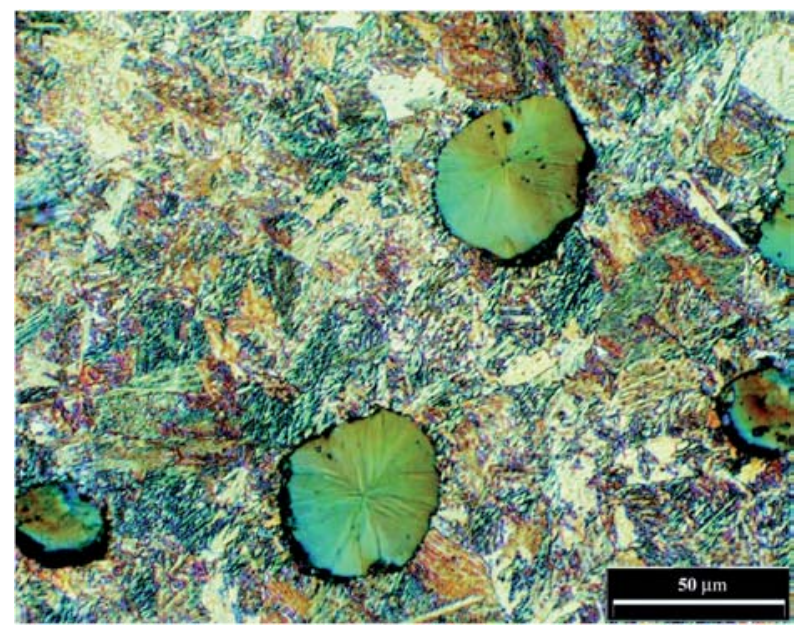

Fig. 2 Structure of ADI transformed during 40 minutes at $400{ }^{\circ} \mathrm{C}$. (Nital etching, the Nomarski method, actual magnification $500 x$ )

cylindrical test bars with a diameter of $6 \mathrm{~mm}$ and length of $30 \mathrm{~mm}$ were used, see Fig. 4. The tests were performed using Zwick 1478 testing device at room temperature, with crosshead velocity of $1 \mathrm{~mm} / \mathrm{min}$ (corresponding strain rate is about $5 \cdot 10^{-4} \mathrm{~s}^{-1}$ ).

Fatigue properties were evaluated by determination of S-N curves and fatigue limits. Fatigue tests were performed on the Amsler high-frequency pulsator (frequency of $180 \mathrm{~Hz}$, room temperature) at symmetrical push-pull loading $(R=-1)$ and repeating tension ( $R=0$, stress ratio $R$ is equal to quotient of lower stress and upper stress of loading cycle). Each of S-N curves was determined using 12 to 15 test bars with a diameter of $7 \mathrm{~mm}$, which were ground to surface roughness $R a=0.4 \mu \mathrm{m}$, see Fig. 5. S-N curves were fitted using nonlinear least square method with three-parameter regression function

$$
\sigma(N)=a N^{b}+\sigma_{\infty}
$$

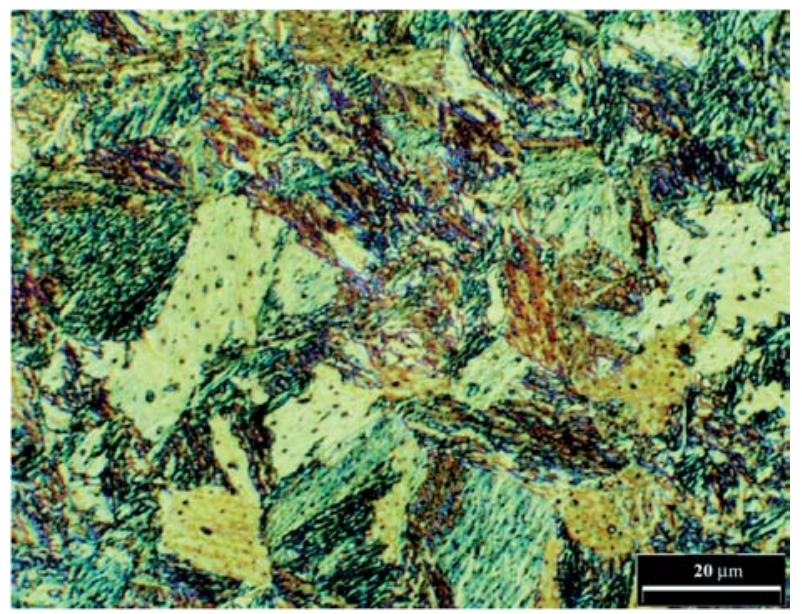

Fig. 3 Structure of ADI transformed during 40 minutes at $400{ }^{\circ} \mathrm{C}$. (Nital etching, the Nomarski method, actual magnification $1000 x$ )
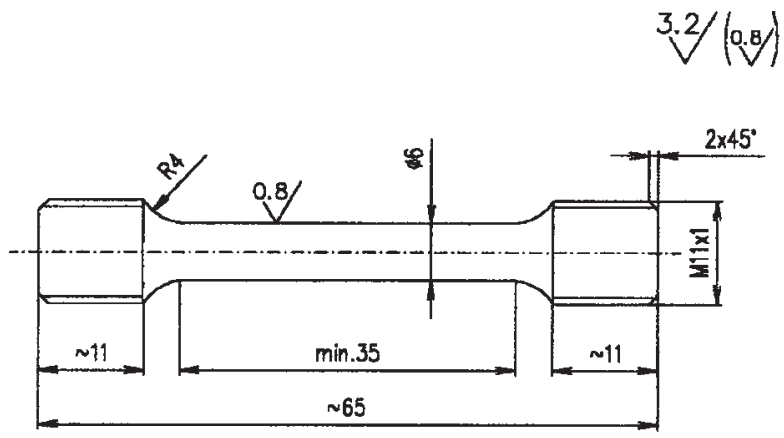

Fig. 4 Test bar for static tensile test (real size)

proposed by Stromeyer and recommended by Weibull [5], which describes very well fatigue behaviour of metals in high-cycle region. The fatigue limits $\sigma_{C}(R=-1)$ and $\sigma_{h C}(R=0)$ for a basic number of cycles to fracture $N_{C}=10^{7}$ were determined directly using the equation obtained by modification of Eq. (2)

$$
\sigma(N)=\left(\sigma_{C}-\sigma_{\infty}\right) \cdot\left(10^{-7} N\right)^{b}+\sigma_{\infty}
$$

which contains fatigue limits as one of regression parameters.

\section{Results}

The results of static tensile tests together with fatigue limits for symmetrical push-pull loading and repeating tensile loading are presented in Table 4. Also the values of parameter $\alpha$ calculated according to the relation

$$
\alpha=\frac{\log \frac{2 \sigma_{C}-\sigma_{h C}}{2 \sigma_{C}}}{\log \frac{\sigma_{h C}}{2 R_{m}}}
$$




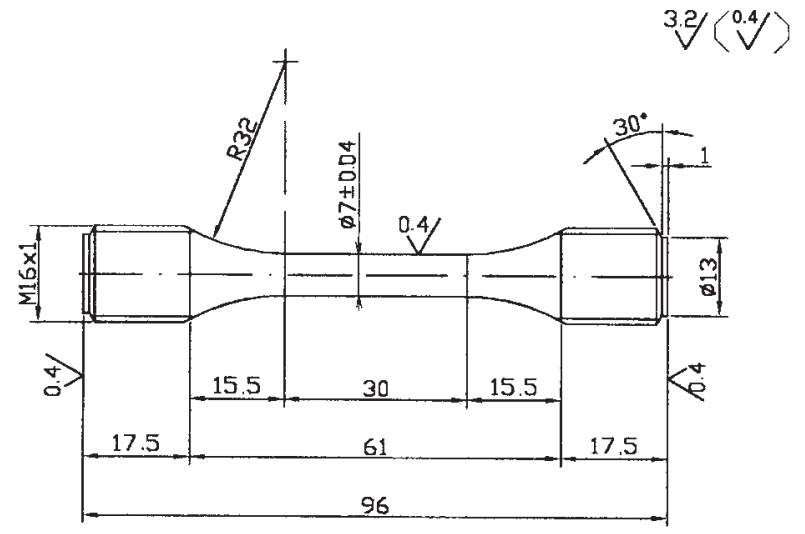

Fig. 5 Test bar for fatigue test (real size)

derived from Eq. (1) are added (natural as well as common logarithms can be used). Individual S--N curves are not presented due to the limited extent of paper. Only some examples of the Haigh diagram and only one example of the Smith diagram are shown, see Figs. 6 to 9 .

\section{Discussion}

In papers [7-9] the Smith diagrams for various types of ferritic-pearlitic nodular cast iron are presented. Their straight-line shapes correspond to the linear Goodman relation. The results of our studies showed that for all 8 studied materials the general relation (1) must be used, see Figs. 6 to 8. The shape of all the Haigh diagrams is convex because the value of exponent $\alpha$ is lower than $1(0<\alpha<1)$, see Table 4 . This behaviour is common for all the studied irons with either ferritic-pearlitic or bainitic structure (in the last years called also ausferrite). The obtained results clearly show that it can be very inaccurate to use the linear Goodman relation for nodular cast irons, especially for ADI. This finding is inconsistent with the mentioned papers [7-9].

Static tensile and fatigue properties

Table 4 of nodular cast irons

\begin{tabular}{|c|c|c|c|c|c|c|c|}
\hline Mater. & $\begin{array}{c}R_{p 0.2} \\
{[\mathrm{MPa}]}\end{array}$ & $\begin{array}{c}R_{m} \\
{[\mathrm{MPa}]}\end{array}$ & $\begin{array}{c}A_{5} \\
{[\%]}\end{array}$ & $\begin{array}{c}Z \\
{[\%]}\end{array}$ & $\begin{array}{c}\sigma_{C} \\
{[\mathrm{MPa}]}\end{array}$ & $\begin{array}{c}\sigma_{h C} \\
{[\mathrm{MPa}]}\end{array}$ & $\begin{array}{c}\alpha \\
{[1]}\end{array}$ \\
\hline F0 & 223 & 361 & 23.7 & 28.6 & 160 & 199 & 0.755 \\
\hline P13 & 417 & 654 & 3.2 & 2.0 & 236 & 317 & 0.786 \\
\hline BH13 & 645 & 881 & 5.4 & 3.4 & 236 & 290 & 0.528 \\
\hline FP15 & 316 & 505 & 16.3 & 13.5 & 186 & 248 & 0.782 \\
\hline P15 & 702 & 1030 & 4.6 & 3.5 & 231 & 333 & 0.700 \\
\hline BH15 & 809 & 1032 & 7.2 & 4.9 & 253 & 370 & 0.764 \\
\hline BP15 & 1036 & 1203 & 3.4 & 1.4 & 241 & 304 & 0.482 \\
\hline BD15 & 1348 & 1531 & 1.1 & 1.0 & 229 & 275 & 0.381 \\
\hline
\end{tabular}

The values of exponent $\alpha$ significantly depend on the matrix of nodular cast iron. The highest values were found for ferritic-

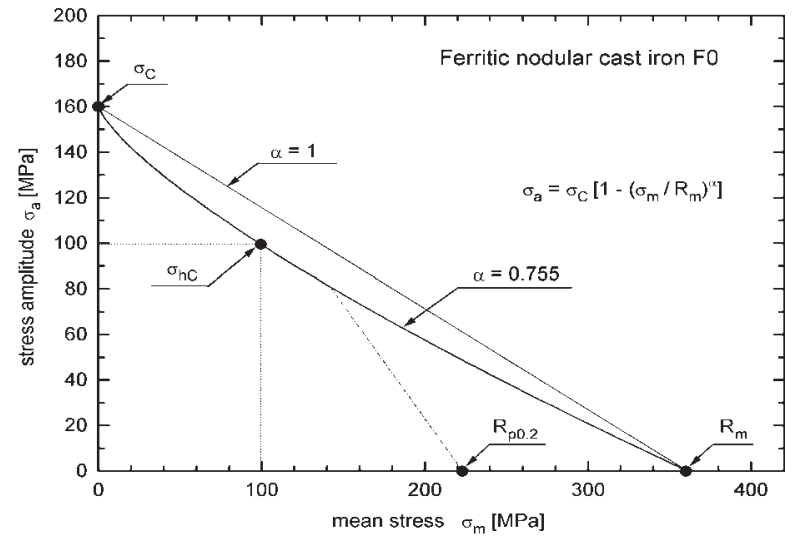

Fig. 6 The Haigh diagram for ferritic nodular cast iron F0

pearlitic irons in the range 0.700 to 0.786 , in which also the value 0.764 for BU15 lies. The values for other types of ADI are lower; the lowest value 0.381 was obtained for BL15. The approximate dependence of this exponent on UTS as one of most important characteristics of the matrices was determined in the form valid for UTS expressed in MPa

$$
\alpha\left(R_{m}\right)=0.943-0.329 \cdot 10^{-3} R_{m} \quad\left(\text { for } R_{m} \text { in } \mathrm{MPa}\right),
$$

see Fig. 10. This relation explicitly shows that the value of exponent $\alpha$ is always lower than 1 and significantly decreases with the increasing UTS [10, 11]. Low $\alpha$ value means that the material is extremely sensitive to the increase of mean stress, especially in the range of small mean stresses.

\section{Conclusions}

On the basis of the study of fatigue behaviour of nodular cast iron with ferritic-pearlitic as well as bainitic matrices (ADI) obtained at various temperatures of isothermal transformation the following conclusions can be formulated:

1. The dependence of the loading cycle amplitude on the mean stress at push-pull loading has a convex shape for all types of nodular cast iron (ferritic-pearlitic as well as ADI).

2. The shape of the Smith and the Haigh diagrams cannot be approximated using the linear Goodman relation, but a general relation containing exponent $\alpha$ lower than 1 must be used.

3. The highest values of exponent $\alpha$ were obtained for ferritic nodular cast iron and for ADI transformed at $400{ }^{\circ} \mathrm{C}$. The lowest value of exponent $\alpha$ was obtained for ADI transformed at $300{ }^{\circ} \mathrm{C}$.

4. The value of exponent $\alpha$ decreases with the increasing UTS not only for ferritic-pearlitic nodular iron, but also for ADI. This relation can be approximately expressed by a linear equation.

\section{Acknowledgments}

Financial supports of the Ministry of Defence of the Czech Republic within the research project MO0FVT0000404 are gratefully acknowledged. 


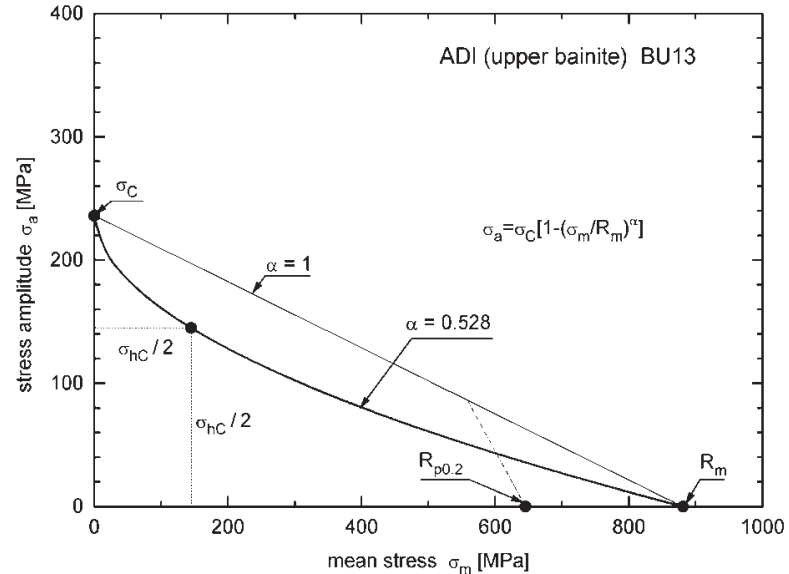

Fig. 8 The Haigh diagram for ADI BU13

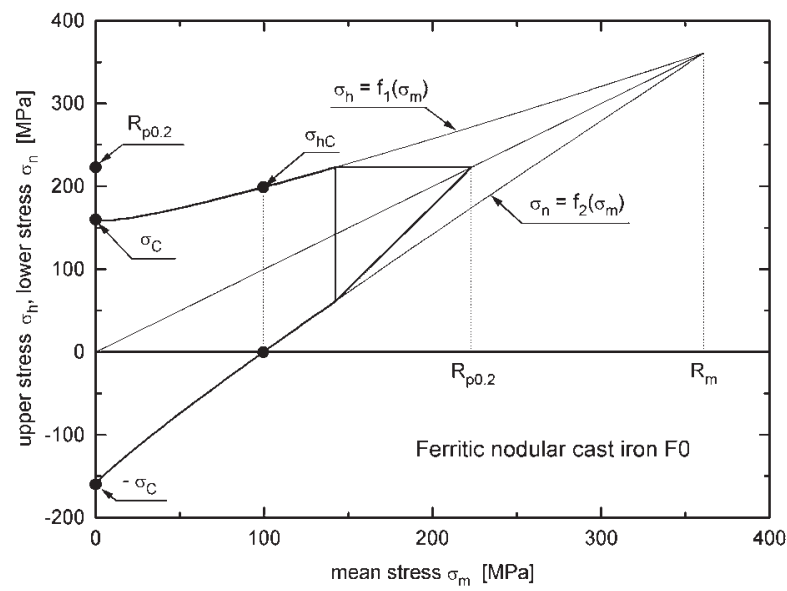

Fig. 9 The Smith diagram for ferritic nodular cast iron F0

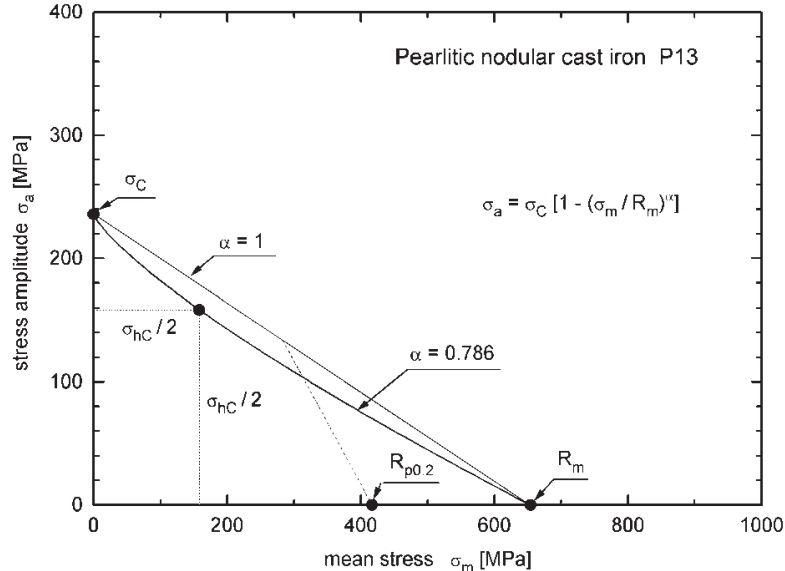

Fig. 7 The Haigh diagram for pearlitic nodular cast iron P13

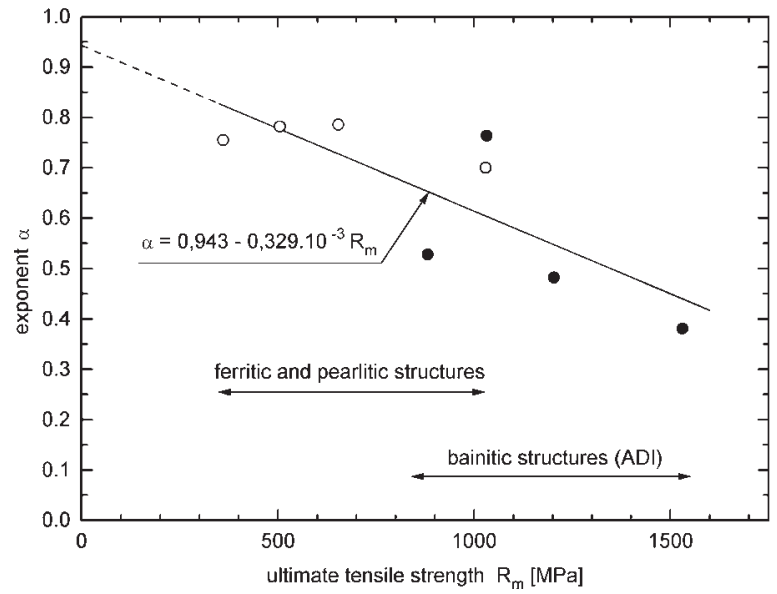

Fig. 10 Dependence of exponent $\alpha$ on ultimate tensile strength $(\bigcirc-$ ferritic and pearlitic structures, $\bullet$ - bainitic structures)

\section{References}

[1] KEOUGH, J. R.: Foundry Management and Technology 123, 1995, No. 11, p. 27.

[2] HARDING, R. A.: Foundryman 86, 1993, p. 197.

[3] VĚCHET, S.: PhD Thesis, Brno University of Technology, Brno 1989, (in Czech).

[4] DORAZIL, E.: High Strength Austempered Ductile Cast Iron. Academia and Horwood, Praha and Chichester 1991.

[5] WEIBULL, W.: Fatigue Testing and Analysing of Results. Pergamon Press, Oxford etc. 1961.

[6] DYLĄG, Z., ORŁOŚ, Z.: Materials Fatigue and its Testing. SNTL, Praha 1968 (in Czech).

[7] TAUSCHER, H.: Dauerfestigkeit von Stahl und Gusseisen (4h edition). VEB Fachbuchverlag, Leipzig 1982.

[8] NIETH, F., WIEGAND, H.: Giesserei-Forschung 29, 1977, p. 131.

[9] JAHN, J. Giessereitechnik 30, 1984, p. 71.

[10] VĚCHET, S., KOHOUT, J.: Foundry Industry 48, 2000, p. 37 (in Czech).

[11] VĚCHET, S., KOHOUT, J., BOKU゚VKA, O.: Fatigue Properties of Nodular Cast Iron. EDIS, Žilina 2001 (in Czech). 